\title{
Experimental Bacterial Endocarditis After Dental Extractions in Rats with Periodontitis
}

\author{
C. Daniel Overholser, Philippe Moreillon, \\ and Michel P. Glauser
}

\author{
From the Department of Oral Diagnosis, Baltimore College \\ of Dental Surgery, Dental School, University of Maryland at \\ Baltimore, Baltimore, Maryland; and the Division des \\ Maladies Infectieuses, Département de Médecine Interne, \\ Centre Hospitalier Universitaire Vaudois, \\ Lausanne, Switzerland
}

\begin{abstract}
The development of bacterial endocarditis was analyzed after dental extractions in rats with or without periodontal disease. Periodontal disease was produced in rats by tying silk ligatures around the two maxillary first molars and placing the animals on a high sucrose diet for 14 weeks. Sterile aortic valve vegetations were produced by means of a transaortic catheter, and $24 \mathrm{hr}$ later the maxillary first molars were extracted. The animals were killed $72 \mathrm{hr}$ after the extractions. In rats with periodontal disease, extractions resulted in a $48 \%$ (14 of 29) incidence of bacterial endocarditis, most cases of which were due to Streptococcus spp. (one was caused by Staphylococcus aureus). In contrast, when the teeth with a healthy periodontium were extracted, only 6\% (one of 15) of the rats developed endocarditis. When catheters were placed in animals with periodontal disease but no extractions were performed, no endocarditis occurr $\mathrm{d}$.
\end{abstract}

Recommendations for antibiotic prophylaxis against bacterial endocarditis after dental procedures are based largely on studies with animal models [1-7]. In these studies, sterile vegetations are produced by insertion of a plastic catheter through the aortic valve of the animal. After administration of an appropriate antibiotic, a large inoculum of a known bacterium is given by iv injection. Such studies have led to an improved knowledge of the natural history of bacterial endocarditis in the rabbit and the rat but obviously have not led to an improved understanding of the relationship between teeth and bacterial endocarditis.

Dental diseases and their treatment have been strongly implicated in the development of bacterial endocarditis in the susceptible individual [8-13]. However, the evidence supporting this hypothesis is circumstantial. An estimated 5\%-50\% of clinical cases

Received for publication 24 March 1986, and in revised form 8 July 1986

This study was supported by grant 3.847-0.83 from the Swiss National Foundation for Scientific Research and by grant DE06516 from the National Institute of Dental Research, National Institutes of Health.

We thank Jose Entenza for technical assistance and Shirl Harbin for secretarial assistance.

Please address requests for reprints to Dr. C. Daniel Overholser Department of Oral Diagnosis, Baltimore College of Dental Surgery, Dental School, University of Maryland at Baltimore, 666 West Baltimore Street, Baltimore, Maryland 21201. of endocarditis are caused by organisms that are natural inhabitants of the oral cavity [12-18]. Various oral manipulations have produced bacteremias linked to bacterial species that are commonly involved with endocarditis [19-21]. Bacterial endocarditis not infrequently follows dental treatment, especially surgical procedures [22]. However, studies in humans that would directly link dentally induced episodes of bacteremia with subsequent bacterial endocarditis cannot be performed for ethical reasons [5].

The present experiment was undertaken to examine the relevance of preexistent periodontal disease on the development of bacterial endocarditis in catheterized rats after the extraction of teeth.

\section{Materials and Methods}

Induction of periodontal disease. Three groups of female Wistar rats (body weight, $180-200 \mathrm{~g}$ ) were studied. Groups 1 and 2 consisted of animals in which gingival irritation was induced when size 000 black silk ligatures were placed at the cervical margins of the maxillary right and left first molars. These ligatures were left in place for the remainder of the experiment. The animals were then maintained on a powdered, high-sucrose diet (Keyes'diet 2000; Teklad, Madison, Wis) ad libitum for 14 weeks. Such a regimen is sufficient to initiate periodontal lesions in the rat [23-25]. Group 3 comprised animals fed a normal diet in the animal facility for 14 weeks. Rep- 
resentative animals were taken from each group and prepared histologically for documentation of the presence of periodontal disease.

Production of sterile aortic valve vegetations. Sterile aortic vegetations were then produced in all animals by a modification of a previously described method [26]. A polyethylene catheter (model PP10; Portex, Hythe, Kent, England) was passed through the aortic valve via the right carotid artery and secured with a silk ligature. The catheter was left in place until the animal was killed.

Dental extractions. Twenty-four hours after catheterization, two teeth - the maxillary right and left first molars - were extracted from the animals in groups 1 and 3. No extractions were performed in group 2 for determination of whether the presence of periodontal disease alone could induce bacterial endocarditis. The two extractions were accomplished in a 4-min period. Immediately after the extractions a $1.0-\mathrm{cm}$ incision was made over the sternoclavicular region, and the left jugular vein was exposed. Blood $(0.5 \mathrm{ml})$ was then drawn via the left jugular vein $1 \mathrm{~min}$ after extraction and plated on blood agar. For technical reasons it was not always possible to obtain this sample. Blood was taken from animals in the nonextraction group (group 2) and treated similarly. The colonies on the pour plates were counted and identified $24-48 \mathrm{hr}$ later.

Killing of animals and evaluation of bacterial endocarditis. Rats were killed $72 \mathrm{hr}$ after extractions, and the aortic vegetations were excised, weighed, homogenized in $1 \mathrm{ml}$ of $0.85 \% \mathrm{NaCl}$, serially diluted, and plated both aerobically and anaerobically. After all animals that did not exhibit vegetations were excluded, 29 animals remained in group 1 and 15 each in groups 2 and 3 . Colony counts were done after incubation for $24-48 \mathrm{hr}$ at $37 \mathrm{C}$. This method permitted the detection of $10^{2} \mathrm{cfu} / \mathrm{g}$ of vegetation. All bacteria were then identified and speciated with use of the API ${ }^{\circledR}$ system (Analytab Products, Plainview, NY).

Histological technique. After fixation in formalin the teeth were decalcified with $5 \%$ formic acid, infiltrated, and embedded in paraffin. Sections were
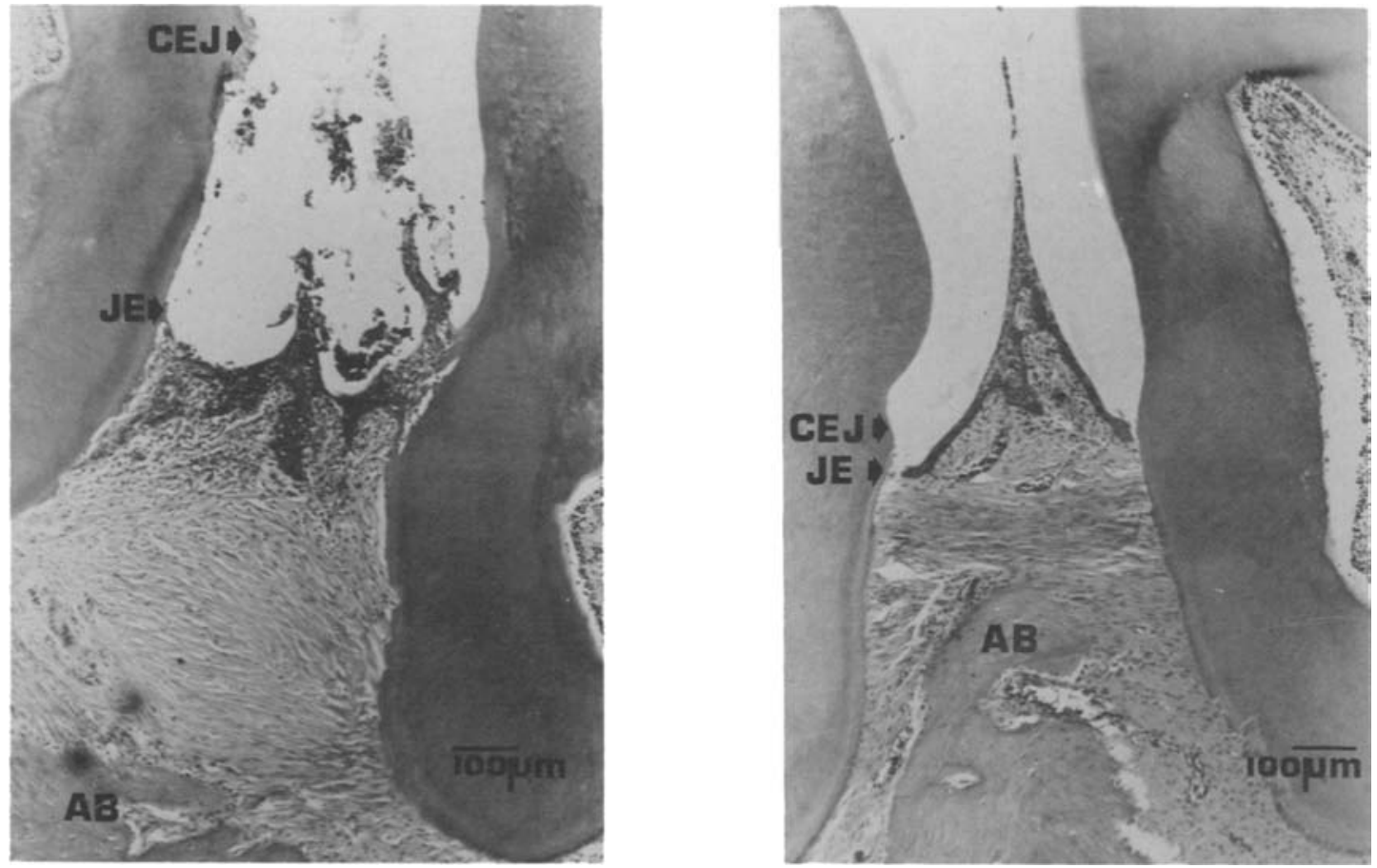

Figure 1. Histological sections of the interdental area between the maxillary first and second molars of rats with (left) and without (right) periodontal disease (stained with hematoxylin and eosin). In rats with periodontal disease, the junctional epithelium $(J E)$ has migrated from near the cementoenamel junction $(C E J)$ toward the root apex (below). A moderate inflammatory response has resulted in resorption of the alveolar bone $(A B)$. The distance between $C E J$ and the level of $A B$ is considerably larger than that in rats without periodontal disease. In the latter animals, note the short distance between $C E J$ and $J E$ and between $C E J$ and $A B$, as well as the diminished signs of inflammation. 
cut at $7 \mu \mathrm{m}$. Every other section was stained with hematoxylin and eosin.

Statistical analysis. The $\chi^{2}$ test with Yates's correction and the Wilcoxon rank sum test were used for statistical analysis.

\section{Results}

Periodontal status. In the animals that had ligatures and that were maintained on the high-sucrose diet (groups 1 and 2), clinical examination before the extractions showed evidence of the presence of periodontal disease. Moderate amounts of plaque had accumulated in the area next to the ligatures. Occasionally this debris appeared and felt calcified when the extractions were performed. The gingiva adjacent to the ligatures appeared erythematous and somewhat enlarged. At least part of the enlargement was due to displacement by the ligatures. In histological examinations of animals from groups 1 and 2 , the junctional epithelium had routinely migrated away from the cementoenamel junction (figure 1, left). The gingiva was moderately inflamed in most specimens and was characterized by increased vascularity, a predominantly PMNL infiltrate, and occasionally resorption of alveolar bone. This loss of bone corresponded to the apical migration of the junctional epithelium.

Clinically the animals in group 3 appeared to have normal gingiva. The gingiva was pink, and there were no clinical signs of inflammation, change in size or architecture, or accumulation of plaque or debris. Histologically the gingiva of the animals also appeared normal (figure 1, right). Few inflammatory cells were noted and seldom were seen in the subjacent connective tissue. The junctional epithelium was invariably near the level of the cementoenamel junction. There was no evidence of alveolar bone loss.

Incidence of endocarditis. Infective endocarditis developed regularly after dental extractions in group 1 rats with periodontitis (14 [48.3\%] of 29), whereas it seldom was found in group 3 rats without periodontitis (one [6.7\%] of 15; table 1). Periodontitis alone without extraction (group 2) did not result in development of endocarditis during the three days after placement of the intracardiac polyethylene catheter. Significantly more bacterial endocarditis was seen in group 1 animals versus either group 2 or group $3(P<.02)$. In all but one case of endocarditis, streptococci were recovered from the vegetations: $\beta$-hemolytic streptococci from 12 rats, $\alpha$-hemolytic streptococci from 2 rats, and $S$. bovis from 1 rat. In one animal, endocarditis was due to Staphylococcus aureus. In all 15 animals with endocarditis the microorganisms grew from the vegetations in pure culture.

In table 1 are also reported the median numbers of bacteria recovered from animals for which cul-

Table 1. Relationship among dental extractions, periodontal disease, and development of bacterial endocarditis in rats with catheter-induced aortic valve sterile vegetations.

\begin{tabular}{|c|c|c|c|c|c|c|}
\hline \multirow[b]{2}{*}{ Type of procedure } & \multirow{2}{*}{$\begin{array}{c}\text { Bacterial } \\
\text { endocarditis }\end{array}$} & \multirow{2}{*}{$\begin{array}{c}\text { No. of rats }(\%) \\
\text { with bacteremia/ } \\
\text { no. tested* }\end{array}$} & \multicolumn{2}{|c|}{ No. of rats with bacteremia } & \multirow{2}{*}{$\begin{array}{l}\text { Median no. of cfu/ml } \\
\text { of blood (range) }\end{array}$} & \multirow{2}{*}{$\begin{array}{c}\text { Incidence of } \\
\text { bacterial } \\
\text { endocarditis }\end{array}$} \\
\hline & & & Monomicrobial & Polymicrobial & & \\
\hline \multirow[t]{2}{*}{ Group 1} & Present & $7 / 8(88)$ & 2 & 5 & $20(0-200)^{+}$ & 14 \\
\hline & $\begin{array}{l}\text { Absent } \\
\text { Total }(\%)\end{array}$ & $8 / 9(89)$ & 1 & 7 & $11(0-58)^{\ddagger}$ & $\begin{array}{l}15 \\
14 / 29(48)^{8}\end{array}$ \\
\hline \multirow[t]{2}{*}{ Group 2} & Present & 0 & 0 & 0 & 0 & 0 \\
\hline & $\begin{array}{l}\text { Absent } \\
\text { Total }(\%)\end{array}$ & $1 / 15(6.7)$ & 1 & 0 & $0(0-2) \ddagger$ & $\begin{array}{l}15 \\
0 / 15(0)\end{array}$ \\
\hline \multirow[t]{2}{*}{ Group 3} & Present & $1 / 1(100)$ & 0 & 1 & $50 \ddagger$ & 1 \\
\hline & Absent & $9 / 12(75)$ & 6 & 3 & $10(0-50)$ & 14 \\
\hline
\end{tabular}

NOTE. Group 1 had periodontal disease and dental extractions, group 2 had periodontal disease but no extractions, and group 3 had no periodontal disease but had extractions.

* For technical reasons, cultures of blood could not be performed for all rats.

$\dagger$ The organisms cultured from rats with bacterial endocarditis were $\beta$-hemolytic streptococei ( 12 rats), $\alpha$-hemolytic streptococci (2 rats), and Streptococcus bovis (1 rat).

\$ The relationship between the total no. of $\mathrm{cfu} / \mathrm{ml}$ of blood $1 \mathrm{~min}$ after dental extractions and the subsequent development of bacterial endocarditis was not significant when tested by the Wilcoxon rank sum test.

$\S P<.05$ when compared with group 2 and group 3 by the $\chi^{2}$ test with Yates's correction. 
tures of blood could be done after dental extractions. Dental extractions produced episodes of bacteremia in a significant number of rats $1 \mathrm{~min}$ after the extractions (groups 1 and 3), a phenomenon not observed in the group that did not receive dental extractions (group 2). Although periodontitis was necessary for consistent development of endocarditis after dental extractions, the median bacterial numbers found after extractions were very similar in rats with normal teeth and in rats with periodontally diseased teeth. Only the incidence of polymicrobial bacteremia was somewhat higher in the latter group. Table 1 also shows the magnitude of bacteremia in rats that subsequently developed endocarditis and in rats that did not. Although the average number of bacteria circulating after the extractions was higher in the animals that subsequently developed bacterial endocarditis, the difference was not statistically significant $(P<0.5)$.

\section{Discussion}

Previous attempts at the development of an animal model for study of the relationship between dental manipulations and subsequent bacterial endocarditis have relied on addition of exogenous bacteria. Bahn et al. [27] produced bacterial endocarditis in catheterized rabbits by introduction of various-sized inocula of bacteria into freshly created oral wounds, a process demonstrating that the oral cavity could be the source of the organisms that produced the endocarditis. However, a routine clinical procedure, such as the extraction of teeth, did not result in bacterial endocarditis unless additional bacteria were inoculated into the extraction site wound. McGowan and Hardie [28] induced bacterial endocarditis in three of 20 catheterized rabbits by extracting teeth while intermittently flooding the field with a suspension of $10^{7}-10^{8}$ washed streptococci $/ \mathrm{ml}$ of broth. The present study has demonstrated that bacterial endocarditis can be consistently produced in catheterized rats when teeth are extracted in the presence of periodontal disease. The necessity for the presence of periodontal disease was seen when bacterial endocarditis rarely developed after extraction of teeth in the absence of periodontal disease. Although periodontal disease alone did not produce bacterial endocarditis in this series of experiments, the interval that animals in this group were at risk for the development of bacterial endocarditis was very short (three days).
Periodontal disease in rats is an infectious process $[23,29]$. Under natural conditions, however, the rat is very resistant to periodontal diseases. The present experiments have confirmed that ligature-induced gingival irritation and addition of a high-sucrose diet reliably induce periodontitis. The large ulcerated area of the gingiva next to the microbially colonized plaque on the tooth surface serves as an excellent portal entry for bacteria during function, dental manipulation, or both.

In humans, periodontal disease occurs spontaneously and reflects the inflammatory response to bacteria that colonize the surface of the tooth contiguous to the gingiva, that metabolize local nutrients, and that elaborate toxins that eventually penetrate the epithelium of the gingival sulcus. This ulceration of the epithelium lining the space between the tooth and gingiva results in a gingival pocket. In the early stages of periodontitis, the connective tissue attachment is lost near the crown of the tooth, and the pocket epithelium begins to migrate apically along the root surface. At this stage a periodontal pocket is recognized. In periodontitis, unlike gingivitis, the inflammation affects the bone homeostasis with a net loss of bony support, which, when advanced, is characterized by mobility and eventual loss of the teeth. Thus gingivitis and periodontitis can be characterized as inflammatory responses to metabolites of a mixed infection established on the tooth surface $[30,31]$. The pocket lining is ulcerated, and the total surface area can become several square centimeters as the pockets deepen.

Bayliss et al. [14] have suggested that "dental sepsis" and the lack of good dental hygiene are important sources of bacteria for the subsequent development of bacterial endocarditis in humans. In their retrospective survey, $48(8.8 \%)$ of 544 patients with bacterial endocarditis had "dental sepsis" but had not had dental treatment in the previous three months. Another 176 patients with infective endocarditis due to viridans group streptococci were considered dentally healthy, and the infection was presumed not to be of dental origin, even though viridans group streptococci are normally found only in the oropharyngeal region. However, criteria to distinguish between subjects considered to have "dental sepsis" or to be "dentally healthy" were not given. Although gingivitis and early periodontitis are certainly not considered to be "dentally healthy," they often remain undiagnosed unless carefully looked for and, in addition, probably would not qualify as 
dental sepsis. It has long been recognized that spontaneous episodes of bacteremia occur in the presence of oral infection $[19,20]$, and thus gingivitis and periodontitis may account for a number of the cases of endocarditis.

In the present experiments there was a surprising lack of correlation between the absolute number of bacteria circulating $1 \mathrm{~min}$ after extraction and the subsequent development of bacterial endocarditis. Studies of endocarditis in rabbits or in rats have demonstrated a relationship between the number of bacteria injected for challenge and the incidence of endocarditis that follows. Although with a given bacterial isolate there was a close relationship between the inoculum size used for iv challenge and the subsequent incidence of endocarditis, wide variations in the ability to induce endocarditis have been observed for similar streptococcal types and among different streptococcal species $[6,32]$. Thus the magnitude of the bacteremia, whether resulting from iv injections or from dental extractions, at a given time might not ipso facto reflect the chances for a given bacterium to induce endocarditis. Factors other than the mere number of bacteria circulating might play an important part in the ability to induce endocarditis, such as the interval the bacteria are circulating after challenge or adherence properties. Further studies are needed to clarify these issues. The significance of the polymicrobial bacteremia might be that several species circulate and therefore may increase the chance for more virulent or more adherent forms to circulate.

In conclusion, we have demonstrated that endocarditis can be reliably produced in rats with catheterinduced aortic vegetations after extraction of periodontally diseased teeth. This model mimics more closely human endocarditis than that induced after iv bacterial challenge. It may permit the study of the relationship between dental manipulations and the subsequent development of endocarditis and the careful testing of antibiotic prophylactic regimens currently recommended for humans.

\section{References}

1. Shulman ST, Amren DP, Bisno AL, Dajani AS, Durack DT, Gerber MA, Kaplan EL, Millard HD, Sanders WE, Schwartz RH, Watanakunakorn C, Members. Prevention of bacterial endocarditis: a statement for health professionals by the Committee on Rheumatic Fever and Infective Endocarditis of the Council on Cardiovascular Disease in the Young. Circulation 1984;70:1123A-7A

2. Working Party of the British Society for Antimicrobial Che- motherapy. The antibiotic prophylaxis of infective endocarditis. Lancet 1982;2:1323-6

3. Durack DT. Prophylaxis of infective endocarditis. In: Mandell GL, Douglas RG Jr, Bennett JE, eds. Principles and practice of infectious diseases. 2nd ed. New York: Wiley, 1985:539-44

4. Durack DT, Petersdorf RG. Chemotherapy of experimental streptococcal endocarditis. I. Comparison of commonly recommended prophylactic regimens. J Clin Invest 1973; 52:592-8

5. Pelletier LL Jr, Durack DT, Petersdorf RG. Chemotherapy of experimental streptococcal endocarditis. IV. Further observations on prophylaxis. J Clin Invest 1975;56:319-30

6. Glauser MP, Bernard JP, Moreillon P, Francioli P. Successful single-dose amoxicillin prophylaxis against experimental streptococcal endocarditis: evidence for two mechanisms of protection. J Infect Dis 1983;147:568-75

7. Heraief E, Glauser MP, Freedman LR. Vancomycin prophylaxis of streptococcal endocarditis in rats. In: Nelson JD, Grassi C, eds. Current chemotherapy and infectious disease. Vol. 2. Washington, DC: American Society for Microbiology, 1980:911-3

8. Lewis T, Grant RT. Observations relating to subacute infective endocarditis. Heart 1923;10:21-99

9. Rushton MA. Subacute bacterial endocarditis following the extraction of teeth. Guy's Hospital Reports 1930;80:39-44

10. Anolik R, Berkowitz RJ, Campos JM, Friedman AD. Actinobacillus endocarditis associated with periodontal disease. Clin Pediatr (Phila) 1981;20:653-5

11. Mostaghim D, Millard HD. Bacterial endocarditis: a retrospective study. Oral Surg Oral Med Oral Pathol 1975;40:219-34

12. Falace DA, Ferguson TW. Bacterial endocarditis. Survey of patients treated between 1963 and 1975. Oral Surg Oral Med Oral Pathol 1976;42:189-95

13. Pogrel MA, Welsby PD. The dentist and prevention of infective endocarditis. Br Dent J 1975;139:12-6

14. Bayliss R, Clarke C, Oakley C, Somerville W, Whitfield AGW. The teeth and infective endocarditis. $\mathrm{Br}$ Heart $\mathrm{J}$ 1983;50:506-12

15. Bayliss R, Clarke C, Oakley C, Somerville W, Whitfield AGW, Young SEJ. The microbiology and pathogenesis of infective endocarditis. Br Heart J 1983;50:513-9

16. Lowes JA, Hamer J, Williams G, Houang E, Tabaqchali S, Shaw EJ, Hill IM, Rees GM. 10 years of infective endocarditis at St. Bartholomew's Hospital: analysis of clinical features and treatment in relation to prognosis and mortality. Lancet 1980;1:133-6

17. Pelletier LL Jr, Petersdorf RG. Infective endocarditis: a review of 125 cases from the University of Washington Hospitals, 1963-1972. Medicine (Baltimore) 1977;56:287-313

18. Everett ED, Hirschmann JV. Transient bacteremia and endocarditis prophylaxis. A review. Medicine (Baltimore) 1977;56:61-77

19. Okell CC, Elliott SD. Bacteriaemia and oral sepsis with special reference to the aetiology of subacute endocarditis. Lancet 1935;2:869-72

20. Lineberger LT, De Marco TJ. Evaluation of transient bacteremia following routine periodontal procedures. J Periodontol 1973;44:757-62

21. Cobe HM. Transitory bacteremia. Oral Surg Oral Med Oral Pathol 1954;7:609--15 
22. Burket LW, Burn CG. Bacteremias following dental extraction. Demonstration of source of bacteria by means of nonpathogen (Serratia marcesens). J Dent Res 1937;16:521-30

23. Rovin S, Costich ER, Gordon HA. The influence of bacteria and irritation in the initiation of periodontal disease in germfree and conventional rats. J Periodontol Res 1966;1:193-203

24. Garant PR, Cho MI. Histopathogenesis of spontaneous periodontal disease in conventional rats. I. Histometric and histologic study. J Periodontal Res 1979;14:297-309

25. Weiner GS, DeMarco TJ, Bissada NF. Long term effect of systemic tetracycline administration on the severity of induced periodontitis in the rat. J Periodontol Res 1979;50: 619-23

26. Bernard J-P, Francioli P, Glauser MP. Vancomycin prophylaxis of experimental Streptococcus sanguis: inhibition of bacterial adherence rather than bacterial killing. J Clin Invest 1981;68:1113-6
27. Bahn SL, Goveia G, Bitterman P, Bahn AN. Experimental endocarditis induced by dental manipulation and oral streptococci. Oral Surg Oral Med Oral Pathol 1978;45:549-59

28. McGowan DA, Hardie JM. Production of bacterial endocarditis in prepared rabbits by oral manipulation. $\mathrm{Br}$ Dent J 1974;137:129-31

29. Dick DS, Shaw JH. The infectious and transmissible nature of the periodontal syndrome of the rice rat. Arch Oral Biol 1966;11:1095-108

30. Socransky SS. Relationship of bacteria to the etiology of periodontal disease. J Dent Res 1970;49(Suppl 2):203-22

31. Slots J. Subgingival microflora and periodontal disease. J Clin Periodontol 1979;6:351-82

32. Francioli P, Glauser MP. Successful prophylaxis of experimental streptococcal endocarditis with single doses of sublethal concentrations of penicillin. J Antimicrob Chemother 1985;15(Suppl A):297-302 